American Journal of Applied Sciences 6 (9): 1725-1730, 2009

ISSN 1546-9239

(C) 2009 Science Publications

\title{
Knowledge and Attitudes of Infertile Male Patients Attending Kamal Alsamaraee Fertility Center about Assisted Reproductive Technique in Practice
}

\author{
${ }^{1}$ Lujain Anwar Al Khazrajy and ${ }^{2}$ Mohammed Ahmed Al Abayechi \\ ${ }^{1}$ College of Medicine, Department of Community Medicine, University of Baghdad, Baghdad, Iraq \\ ${ }^{2}$ Kamal Al Samaraee Fertility Center, IVF Lab. Department, Baghdad, Iraq
}

\begin{abstract}
Problem statement: The aim of this survey was to show the knowingness and standings of infertile male patient that attending Kamal Al Samaraee fertility center, about IVF and IUI procedures in clinical practice. Approach: A cross sectional study done and data were collected during two months period using special form of questionnaire, the total sample was 203 male patients Were performed using descriptive rates and percentages, procedures included Pearson's product- moment correlation were included. Results: The first part showed the demographic data and there was a significant positive correlation between the patient's knowledge about (ART) and level of education ( $\mathrm{r}$ $=0.703988)$ and their knowledge and duration of infertility $(\mathrm{r}=0.607133)$ respectively. The second part of the study showed lack of knowledge about some aspects of assisted reproductive technique as a procedure and as a technical details, most of the participant don't know whether IUI need general anesthesia or not (41\%), the same thing is true for (IVF) technique, also $41 \%$ of the sample didn't know whether fertilization of ova done outside the wife body or not., the third part showed the attitudes of participants were (80\%) of the participants refused gamete donation. Conclusion: it was obvious that there was lack of knowledge about many aspects of (ART), also the attitudes of the participants was highly influenced by cultural and religious believes therefore, education is needed to make the general community aware of the various aspects of (ART), on the other hand we recommended that a governmental legislative and financial support should be made for the promotion of assisted reproductive technique in Iraq.
\end{abstract}

Key words: Assisted Reproductive Technique (ART), In Vitro Fertilization (IVF), Intrauterine Insemination (IUI)

\section{INTRODUCTION}

Infertility affects between $8-20 \%$ of couples around the world at some stage during their reproductive years ${ }^{[1]}$, it has become a communal problem in terms of not only the couples involved, but also their health team and the social environment ${ }^{[2]}$.

The level and patterns of infertility varies widely, being found less in developed countries and more in underdeveloped countries ${ }^{[3]}$. Efficient treatment for infertility is time-consuming, expensive and often unsuccessful $^{[4]}$, not enough importance has been given to the provision of infertility services, a state reflected in most of developing countries ${ }^{[5]}$. In the past three decades, three striking changes have occurred in infertility practice, namely the introduction of Assisted Reproductive Technology (ART), a marked increase in patient visits for infertility and an increase in the proportion of women over age 35 years seeking medical attention for infertility ${ }^{[6]}$. Assisted reproductive technology is a general term referring to methods used to achieve pregnancy by artificial or partially artificial means. It is reproductive technology used in infertility treatment, which is the only application routinely used today of reproductive technology ${ }^{[7]}$.

The Centers for Disease Control and Prevention (CDC) at US fertility clinics-defines ART to include "all fertility treatments in which both eggs and sperm are handled. In general, ART procedures involve surgically removing eggs from a woman's ovaries, combining them with sperm in the laboratory and returning them to the woman's body or donating them to another woman ${ }^{[8]}$.

In Iraq the first fertility center was established at Al-Elwyia hospital in 1975, the first successful Intra Uterine Insemination (IUI) done in 1984. The In Vitro Fertilization technique (IVF) started first at the end of 1989 and the first successful (IVF) done at 1990 and resulted in quadruplet ${ }^{[9]}$. 


\section{MATERIALS AND METHODS}

Design: Survey time of study: From 1st of Jan. 2009, 28 Feb. 2009.

Sampling and subjects: All infertile male patients attending Kamal Alsamaraee fertility Center in Baghdad- Iraq, which equal to 210, only 203 agreed to fill in the questionnaires.

Development of questionnaire: The questioner is composed of 23 questions, in its first part, the patient were asked to state their demographic characteristics, the second part of questioner show the knowledge of infertile male patients about (ART) assisted reproductive technique, the third part show the different attitudes of patients about ART.

Statistical analysis: Were performed using descriptive rates and percentages, procedures included Pearson's product- moment correlation were included.

\section{RESULTS}

Demographic information: This includes age with mean age of (35.67) year, occupation, level of education which was divided into 5 levels, starting from primary school and duration of fertility which was divided in to 5 categories.

Data were organized in three parts. The first part of questionnaire that concerns with the demographic characteristics shows a positive correlation between the duration of infertility, level of education and knowledge of the patient about (ART) technique, as shown in Fig. 1 and 2 respectively.

Knowledge: About $50.7 \%$ of the participant believe that infertility is considered a problem if the couple fail to conceive after one year of marriage, while $3 / 4$ of the sample think that sexually transmitted diseases is one of the causes of infertility .

Nearly $2 / 3$ of the participants $(68.5 \%)$ think that type of food effect's on infertility, on the other hand only $22.6 \%$ give right answer about question 4 that declare that the building worker is the only occupation that does not affect fertility.

Kamal Alsamaraee center is the main source of information about ART (48.2\%), while family doctor play minimal role as a source of information $(17.7 \%)$ (Fig. 3).

About $33 \%$ of the sample believes that the wife is the cause when IUI is performed, while $41 \%$ believe that the wife is the cause when IVF is performed.

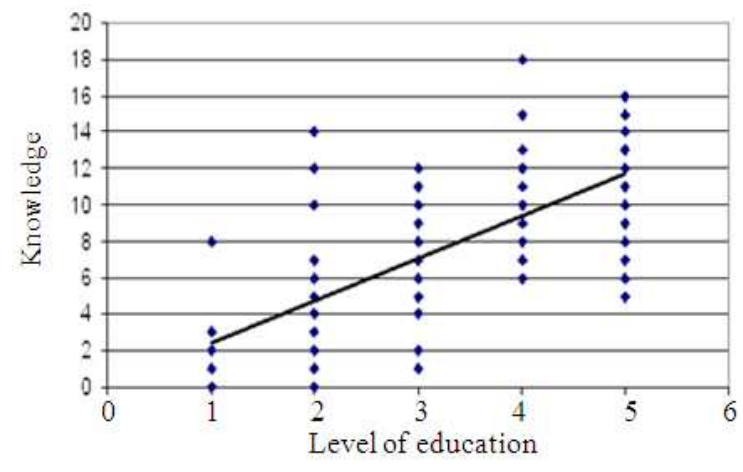

Fig. 1: Correlation between levels of education and knowledge of participants about (ART); Assisted Reproductive Techniques (ART) $r=0.703988$

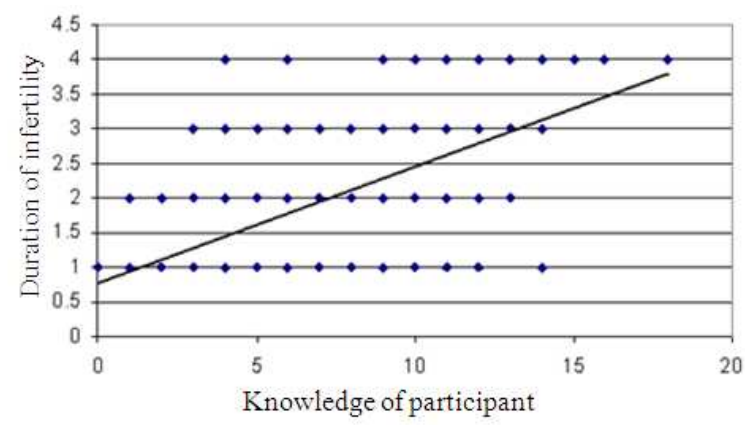

Fig. 2: Correlation between duration of infertility and knowledge of participants about (ART); Assisted Reproductive Techniques (ART) $r=0.607133$

Table 1: Need for general anesthesia during performance of IUI

\begin{tabular}{lcc}
\hline IUI needs general anesthesia for the wife & No. & Percent \\
\hline Yes & 52 & 25.6 \\
No & 66 & 32.5 \\
I don't know & 85 & 41.9 \\
Total & 203 & 100.0 \\
\hline
\end{tabular}

IUI: Intra uterine insemination

Table 2: Site of fertilization of ova in IUI

\begin{tabular}{lrc}
\hline Fertilization of ova done outside the wife body & No. & Percent \\
\hline Yes & 40 & 19.7 \\
No. & 79 & 38.9 \\
I don't know & 84 & 41.4 \\
Total & 203 & 100.0 \\
\hline
\end{tabular}

Table 1 shows most of the participant don't know whether IUI need general anesthesia or not (41\%), the same thing is true for (IVF) technique were $43.9 \%$ of the sample don't know whether there is need for general anesthesia or not. and also for Table 2 were $41 \%$ of the sample doesn't know whether fertilization of ova done outside the wife body or not. 
Am. J. Applied Sci., 6 (9): 1725-1730, 2009

Table 3: Effect of age on IVF success

\begin{tabular}{lrc}
\hline Does age effect IUI & No. & Percent \\
\hline Yes & 121 & 59.6 \\
No. & 30 & 14.8 \\
I don't know & 52 & 25.6 \\
Total & 203 & 100.0 \\
\hline
\end{tabular}

IVF: In Vitro Fertilization

Table 4: Probability of occurrence of multiple pregnancies during performance of (IVF)

\begin{tabular}{lrc}
\hline Occurrence of multiple pregnancies & No. & Percent \\
\hline Yes & 86 & 42.4 \\
No. & 22 & 10.8 \\
I don't know & 95 & 46.7 \\
Total & 203 & 100.0 \\
\hline
\end{tabular}

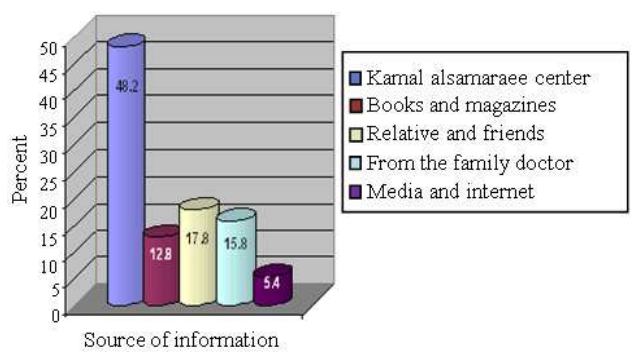

Fig. 3: Sources of information of participants about ART technique

About $37.9 \%$ believes that fertilization of the ova is done outside the wife body if (IVF) is performed. While $(49.8 \%)$ of the sample agree that the sperm can be taken from the testes when IUI is performed, on the other hand $(45.3 \%)$ of the sample believe so if (IVF) is performed.

More than half of the sample number believes that age effect's the IUI successes (51.2\%). The same thing is true for the effect of age on IVF technique $(59.6 \%)$ as shown in Table 3.

About $55.7 \%$ of the participants believe that follicular stimulating drugs affect the intelligence of the borne babies, while, only $42.4 \%$ believe that there's probability of occurrence of multiple pregnancies, as shown in Table 4.

About $(63.1 \%)$ of the sample don't know about the frozen technique. and the type of tissue that we use it for.

Attitudes: The attitudes of the participants were influenced by the cultural and religious believes.

Ten-nearly $(80 \%)$ of the participants refuse to donate sperms ,the same thing is true for ova donation were $(79.3 \%)$ refuses to donate ova as shown in Fig. 4 and 5 respectively.

Nearly $(60.1 \%)$ of the participants agree on sex determination of the embryo.
Table 5: Percent of success of IVF in the world

\begin{tabular}{lcc}
\hline Percent & No. & Percent \\
\hline $0-20$ & 13 & 6.4 \\
$20-40$ & 74 & 36.5 \\
$40-60$ & 74 & 8.4 \\
$60-80$ & 53 & 26.1 \\
$80-100$ & 46 & 22.6 \\
Total & 203 & 100.0 \\
\hline
\end{tabular}

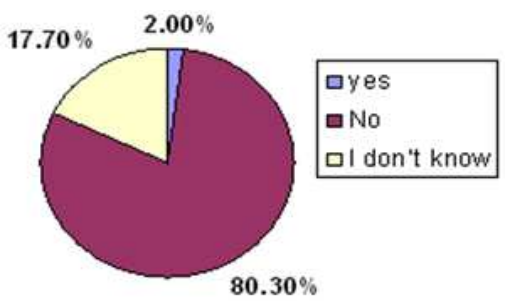

Fig. 4: Agreement of participants on sperm donation

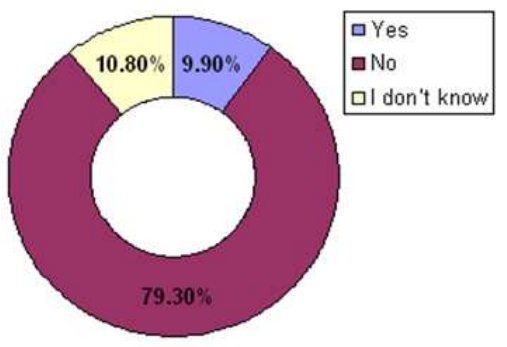

Fig. 5: Agreement of participants on OVA donation Nearly $(60.1 \%)$ of the participants agree on sex determination of the embryo

About $36.5 \%$ of the patients believe that the percent of successes of IVF in the world lies between $(20-40 \%)$, as shown in Table 5.

\section{DISCUSSION}

\section{Knowledge:}

Definition of infertility: Infertility is defined as the inability to conceive after one year of unprotected sexual intercourse roughly $40 \%$ of cases involve a male contribution or factor, $40 \%$ involve a female factor and the reminder involve both sexes ${ }^{[10]}$. About $77 \%$ of the sample agrees with this statement.

Effect of sexually transmitted diseases: Nearly $3 / 4$ of the studied sample (75\%) believes that sexually transmitted diseases affect fertility, recent studies conducted by the World Health Organization (WHO) showed that throughout the world, $38 \%$ of infertility cases were caused by sexually transmitted diseases. If left untreated, the risk factor for tubal-factor infertility 
is doubled with each incidence of PID and severe infections put women at a five times greater risk for infertility than mild infections. Meanwhile, prompt treatment of PID can lower the infertility risk component by three times ${ }^{[11]}$.

Effect of food on fertility: Food affects female fertility in many ways- it's not just your main source of energy! If the female overindulge in a certain taste, she'll affect her chances of getting pregnant. It's not just the amount of food she eats'; it's the imbalance of certain tastes that affect her fertility levels ${ }^{[12]}$. "The different tastessweet, spicy, sour, bitter, salty and aromatic-have certain effects when taken in moderation," writes Randine Lewis in The Infertility Cure ${ }^{[13]}$. "However, if any of these tasted predominate, they can create imbalance in the body. In our study about $2 / 3$ of the studied sample $(68.5 \%)$ agrees that type of food may affect fertility.

Occupation that not affect fertility: Certain occupations may affect fertility like, driver, steel wilding worker, baker, chemical worker, other occupations have no effect like building worker and in our study only $22.6 \%$ of the sample gives right answer declaring that.

Sources of information about (ART): About (48.2\%) of survey sample gain their information about (ART) Kamal Alsamaraee center while other sources of information like media, books or websites, family doctor plays a minor role in such type of health education, perhaps because the concept of family doctor is not well established in Iraq, in a similar study done in Iran about $73 \%$ of the participant gain their knowledge from infertility clinic of Vali-e-Asr were the study done $^{[14]}$.

Performance of IUI and IVF if the wife was the cause: ART includes "all fertility treatments in which both eggs and sperm are handled. In general, ART procedures involve surgically removing eggs from a woman's ovaries, combining them with sperm in the laboratory and returning them to the woman's body or donating them to another woman ${ }^{[8]}$. "So using (ART) as a technique does not depend on whether the wife was the cause or not, In our study only (38.4\%), of the participants agree on that with IUI technique, while $(44.8 \%)$ of the participants agree with that with IVF technique.

The need for general anesthesia during performance of IUI, IVF: Nearly $(32.5 \%)$ of the studied sample believe that there is no need for general anesthesia with IUI technique, on the other hand $(31 \%)$ of the sample believes that general anesthesia is mandatory with IVF technique.

Site of Fertilization of ova during performance of IUI, IVF: IUI does not involve egg retrieval or embryo transfer. It does require the woman to undergo fertility drugs in order to stimulate an increased production of $\operatorname{eggs}^{[14]}$ while in IVF technique, the doctor is able to retrieve the eggs when they are mature but before the woman ovulates them herself. The doctor then retrieves the eggs. The follicle contents (including the eggs) are then drawn up the needle by gentle suction and afterwards placed in a dish in the laboratory. Around 50,000 of the partner's best quality sperm are selected, added to the dish as well and allowed time for fertilization to occur ${ }^{[15]}$. In our study only $(38.9 \%)$ of the participants believe that the ova are fertilized outside the wife body with IUI technique, while $(37.9 \%)$ of the sample studied believe that ova are fertilized outside the wife body with IVF technique.

Taking sperms from the testes during performance of IUI, IVF: About (49.8\%) of the sample agree that the sperms can be taken from the testes with IUI (which is a wrong answer), while $(45.3 \%)$ thinks that the sperm can be taken from testes with IVF technique. It is obvious from the answers of participants for this question and the previous question that there is lack of knowledge about the technical part of (ART) this is due to general educational and scientific retardation that Iraqi people had sufferer during years of sanction and wars that Iraq had went through.

Effect of age on (ART) success rate: About (51.25\%) of the sample thinks that age effect the success rate of IUI while $(59.6 \%)$ of the participants agree that the age affect the success rate of IVF technique. Woman's age is a major factor in conception. The older a woman is the less chance she has of conceiving naturally. The delay in childbearing in Australia has been mirrored by an increasing trend of women aged 35 years or older entering the IVF program. In 2000, with increasing age in a woman, the quality of oocytes decline and the oocyte suitability for use in assisted conception decreases. Older women were more likely to use donor oocytes or donor embryos to achieve pregnancy ${ }^{[16]}$.

Effect of follicular stimulating drugs on IQ of ART delivered babies: More than half of the sample $(55.7 \%)$ of the sample believes that the follicular stimulating drugs, affect the IQ of the born babies of ART. 
Multiple pregnancy and IVF: About $(42.4 \%)$ of the sample believe that ART may result in multiple pregnancies. Multiple pregnancies, usually referred to as multiple gestations, are one in which more than one fetus develops simultaneously in the mother's womb. The frequency of multiple births in the United States has been steadily increasing with advances in reproductive technologies. It is estimated that pregnancies resulting from assisted technologies have a $25-30 \%$ incidence of twins and a 5\% incidence of triplets $^{[17]}$. The frequency of naturally occurring twins is approximately one in 80 births; however the frequency of multiple births in the United States for 2002 was as follows:

Twins, one in 32 triplets, one in 583 quadruplets, one in 9,267 quintuplets and up, one in 58,286 Twin birth is by far the most common multiple birth ${ }^{[16]}$.

Usage of frozen technique in preserving certain tissues during performance of (ART) technique: About $(63.1 \%)$ of the sample don't know about frozen technique and to what type of tissue is used, this because this question is rather technical and sophisticated to be answered correctly by ordinary people.

\section{Attitudes: \\ Causes of hesitation or termination of performance of (ART) technique: About $(47.8 \%)$ of the sample hesitate to do ART technique because of cultural background and believes, a similar result was obtained in a research done in India. The religious practices of these people are spread over a wide canvas in which almost all the major religions of the world are represented. Hindus comprise the majority of the Indian population. Such population diversity makes it difficult to identify a single common Indian viewpoint on the moral and philosophical aspects of assisted reproduction. However, India has national guidelines in place that cover most of the ethical and legal aspects of assisted reproduction. This highlights some of these aspects of the Indian viewpoint ${ }^{[18]}$.}

Gamete donation during performance of (ART) technique: About $(80.3 \%)$ of the participants refuse's to donate sperm while $(79.3 \%)$ refuse's ova donation. those who agree on gamete donation mostly, with long duration of infertility who undergo treatment for many years. and again cultural believes play a major role for the responses of the participants

Sex determination during performance of (ART) technique: About $(60.1 \%)$ of the sample refuse's sex selection during performance of ART.

\section{CONCLUSION}

From the result that we obtained from our research, it was clearly shown that education is needed to make the general community aware of the various aspects of (ART), a referral system should be applied for the patients to all fertility centers, in order to filter the suitable cases, on the other hand we recommend that a governmental legislative and financial support should be made for the promotion of assisted reproductive technique in Iraq.

\section{REFERENCES}

1. World Health Organization (WHO), 1984. Report of the meeting on the prevention of infertility at the primary health care level. Geneva. http://www.popline.org/docs/0659/029147.html

2. Zagar, A.H., A.I. Wani, S.R. Masoodi, B.A. Lawway and M. Salahuddin, 1997. Epidimiologic and etiological aspect of primary infertility in the Kashmir region of India. Fertil. Steril., 68: 637-643. http://cat.inist.fr/?aModele $=$ afficheN\&cpsidt $=2853$ 801

3. Cast, W., T.M. Farley and P.J. Rowe, 1985. Worldwide patterns of infertility: Is Africa different? Lancet, 2: 596-598. PMID: 2863605

4. Puttemans, P., W. Ombelet and I. Brosens, 1995. Reflections on the way to conduct an investigation of subfertility. Hum. Reprod., 10: 80-89. http://humrep.oxfordjournals.org/cgi/content/abstra ct/10/suppl_1/80

5. Rowe, P.J., 1999. Clinical aspects of infertility and the role of health care services. Reprod. Health Matters, 1: 103-111. http://www.jstor.org/pss/3775710

6. Speroff, L., R. Glass and N.G. Kase, Clinical Gynecologic Endocrinology and Infertility. 6th Edn., Baltimore, Lippincott, pp: 1200.

7. Hansen, M., C. Bower, E. Milne, N. de Klerk and J.J. Kurinczuk, 2005. Assisted reproductive technologies and the risk of birth defects--a systematic review. Hum. Reprod., 20: 328-338. PMID: 15567881

8. Olson, C., K. Keppler-Noreuil, P. Romitti, W. Budelier and G. Ryan et al., 2005. In vitro fertilization is associated with an increase in major birth defects. Fertil. Steril., 84: 1308-1315. DOI: 10.1016/j.fertnstert.2005.03.086

9. Jabri, N.N., F.K.H. Buni, J. Ayham, M. Bushra and B.A. Majeed, 2008. To know more about Kamal Al Samaraee Fertility center. 
10. Tanagho, E.A., D.R. Smith and J.W. McAninch, 2000. Smith's General Urology: Male infertility PAUL J. McGraw-Hill Medical Publishing Division, pp: 750.

11. Hatcher, R.A., J. Trussell, F. Stewart and R.H. Hatcher et al., 1998. Contraceptive Technology. 7th Edn., Ardent Media, ISBN: 0966490207, pp: 851.

12. Female Infertility, getting Pregnamt, health, Naturppathic Medcine, Laurie PK, November 16, 2008

13. Holland, J.R., 2009. The infertility cure by Randine Lewis. http://www.bellaonline.com/articles/art1509.asp

14. Sohrabvand, F. and M.D.M. Jafarabadi, 2005. Knowledge and attitudes of infertile couples about assisted reproductive technology. Iranian J. Reprod. $\quad$ Medi., $\quad 3$ 90-94. http://www.ijrm.ir/library/upload/article/90-94.pdf

15. Cooper, S. and S.G. Ellen, 1999. Choosin Assisted Reproduction: Social, Emotional and Ethical Considerations. Perspectives Press, Indianapolis, ISBN: 10: 0944934226, pp: 400.
16. Australian Institute of Health and Welfare (AIHW), National Perinatal Statistics Unit, 2003. Australia's Mothers and Babies 2000. AIHW National Perinatal Statistics Unit, ISBN: 13: 9781740242615, pp: 106.

17. Zaib-un-Nisa, S., S. Ghazal-Aswad and P. Badrinath, 2003. Outcome of twin pregnancies after assisted reproductive techniques a comparative study: Eur. J. Obstet. Gynecol. Reprod. Biol., 109: 51-54. http://linkinghub.elsevier.com/retrieve/pii/S030121 1502004682

18. Anand Kumar, T.C., 2007. Ethical aspects of assisted reproduction: An Indian viewpoint. Reprod. Biomed. Online, 14: 140-142. http://cat.inist.fr/?aModele $=$ afficheN\&cpsidt $=1852$ 3330 